\title{
Conselhos e conferências de saúde no Brasil: uma revisão integrativa
}

\author{
Health councils and conferences in Brazil: an integrative review
}

Berenice Temoteo da Silva (https://orcid.org/0000-0003-0951-3489) ${ }^{1}$

Isabel Maria Sampaio Oliveira Lima (https://orcid.org/0000-0002-9833-3721) ${ }^{2}$
${ }^{1}$ Instituto de Saúde Coletiva, Universidade Federal da Bahia. R. Basílio da Gama s/n, Canela. 40110-040 Salvador BA Brasil.berenicenfer2007@ hotmail.com

${ }^{2}$ Programa de Pós-

Graduação em Família na Sociedade Contemporânea, Universidade Católica do Salvador. Salvador BA Brasil.

\begin{abstract}
This paper aimed to identify the thinking currents used for scientific production on health councils and conferences, from 1990 to 2017. This is an integrative review of literature carried out at the SciELO, LILACS and CAPES journals portals that resulted in the selection of 152 papers. They were analyzed by year of publication, author's institutional origin, dissemination media, object and type of study and theoretical approach. We identified that a gradual increase occurred in the number of publications over the study period and most empirical studies (92.8\%) do not explicitly state the use of any theoretical approach in data analysis. The structuralist, post-structuralist and neo-institutionalist approaches used were mediated by a theoretical model, medium-range theories and concepts of authors of the European, North American and Latin American traditions. The knowledge produced about health council and conference in Brazil may benefit even more from the density of theoretical approaches to social and political sciences.
\end{abstract}

Key words Health Councils, Health Conferences, Participation, Knowledge
Resumo Oobjetivo desse artigo consiste em identificar as correntes de pensamento utilizadas para a produção científica sobre conselhos e conferências de saúde, no periodo de 1990 a 2017. Trata-se de uma revisão integrativa de literatura realizada nas bases SciELO, LILACS e portal de periódicos da CAPES que resultou na seleção de 152 trabalhos. Estes foram analisados segundo ano de publicação, procedência institucional dos autores, veículo de divulgação, objeto e tipo de estudo e abordagem teórica. Identificou-se um aumento gradativo no número de publicações ao longo do periodo estudado, sendo que a maioria dos estudos com base empírica $(92,8 \%)$ não explicita, nominalmente, a utilização de qualquer abordagem teórica na análise dos dados. As abordagens estruturalista, pós-estruturalista e neo-institucionalista utilizadas foram mediadas por modelo teórico, teorias de médio alcance e conceitos de autores da tradição européia, norte-americana e latino-americana. O conhecimento produzido sobre conselho e conferência de saúde no Brasil pode se beneficiar ainda mais da densidade das abordagens teóricas das ciências sociais e políticas.

Palavras-chave Conselhos de Saúde, Conferência de Saúde, Participação, Conhecimento 


\section{Introdução}

Assim como a conquista do direito à saúde, os conselhos e as conferências de saúde advêm da ação política do movimento da Reforma Sanitária Brasileira $(\mathrm{RSB})^{1}$. A dinâmica da interlocução do movimento da RSB nos espaços de poder imprimiu, tanto na Constituição quanto na Lei $8.142 / 90$, estas arenas de participação no processo político de planejamento e gestão da política de saúde, com a imprescindibilidade dos atores sociais. Dessa forma, os conselhos e conferências de saúde constituem canais abertos para a participação da sociedade civil na definição e condução das políticas de saúde, representando um avanço na democratização dessa política².

No Sistema Único de Saúde (SUS) os conselhos e conferências de saúde ocupam a condição de instância formal de exercício de participação da comunidade na construção das políticas de saúde. Com a perspectiva de expressar as demandas sociais e de saúde da população, as conferências definem os princípios e diretrizes que devem orientar todo o processo de formulação das políticas de saúde. Já os conselhos de saúde, por sua vez, consolidam as decisões definidas nas conferências formulando e fortalecendo as políticas de saúde e estabelecendo estratégias para fiscalizar, avaliar e controlar a execução dessas políticas por parte do poder executivo 3 .

A expressiva quantidade desses espaços formais de exercício de participação pelo país indica maiores possibilidades para a democratização da saúde, nos moldes de uma democracia deliberativa, ao mesmo tempo em que provocou o crescente interesse de pesquisadores ${ }^{4,5}$. Desde a sua institucionalização em 1990, as instâncias qualificadas de afirmação do direito à saúde no Brasil têm sido amplamente debatidas na literatura científica, principalmente no que se refere às dimensões da representação, das formas de participação, dos interesses defendidos nesses espaços, da dinâmica interna de funcionamento e estudos evidenciando os limites e as potencialidades desses colegiados ${ }^{6-9}$.

Revisões de literatura sobre o tema permitiram, entre outros aspectos, sistematizar os principais fatores relacionados ao processo de institucionalização das arenas de participação, o entendimento da academia acerca da participação da sociedade na área da saúde, bem como as dimensões da participação já estudadas ${ }^{10-16}$. Contudo, ainda não foram sistematizadas as principais abordagens teórico-metodológicas que têm sido utilizadas nos estudos sobre o tema.
Evidenciar como a produção científica sobre conselhos e conferências de saúde se apropria de correntes teóricas para pensar e analisar a realidade concreta dessas instâncias participativas consiste no desafio que precisa ser enfrentado, especialmente na atual conjuntura de desrespeito a esses colegiados, cuja participação tem sido prescindida no processo de reformulação de políticas de saúde específicas ${ }^{17}$. Esse estudo se propõe a abrir caminhos nessa perspectiva e, mesmo que não tenha a pretensão e até mesmo a competência de esgotar o debate teórico sobre o tema, buscou-se identificar as correntes de pensamento utilizadas para a produção científica sobre conselhos e conferências de saúde, apontando suas possíveis potencialidades no trato da análise dos espaços de disputa dos conselhos e conferências de saúde.

\section{Método}

Trata-se de uma revisão integrativa de literatura que buscou responder a seguinte questão: quais os referenciais teórico-metodológicos utilizados e explicitados nos estudos sobre conselhos e conferências de saúde no Brasil, publicados entre 1990 e 2017? A data de início do recorte temporal corresponde ao ano de institucionalização dos conselhos e conferências de saúde no Brasil pela Lei 8.142/1990. Enquanto o ano de 2017 foi o período final de realização da pesquisa.

A busca foi iniciada em março de 2014 e atualizada anualmente até maio de 2017. Nas atualizações das buscas realizadas em 2015, 2016 e 2017 a variável ano de publicação foi filtrada considerando o período entre o ano da última coleta até aquele momento. Nas bases de dados SciELO, LILACS e portal de periódicos da CAPES, os descritores utilizados foram "participação social", "participação cidadã", "participação comunitária", "conselhos de saúde" e "conferência de saúde". Os descritores contendo a palavra participação foram cruzados individualmente utilizando o operador booleano "and" com "conferência de saúde" e, igualmente com "conselhos de saúde". O cruzamento foi realizado nos formulários avançados e se não existentes, nos formulários livres das bases de dados. Essa estratégia de busca foi utilizada no portal de periódicos da CAPES com os descritores em inglês, conforme preconizado nessa base. $\mathrm{O}$ acesso às bases se deu pelo portal de periódicos da CAPES, mediante o acesso remoto ao conteúdo assinado pelo referido portal para a Universidade Federal da Bahia. 
Os critérios de inclusão foram os seguintes: artigos, em português, publicados no período entre 1990 e 2017, produzidos a partir de conselhos e conferências de saúde do Brasil, já que a intenção foi estudar esses colegiados participativos na dinâmica social do país e, mais ainda, pesquisar os espaços deliberativos inseridos no contexto singular do SUS. Os artigos que, mesmo tratando da temática de participação no âmbito da saúde, não se referiam aos conselhos e/ou às conferências de saúde foram excluídos.

A seleção dos artigos ocorreu mediante a leitura dos títulos e resumos, o que permitiu a exclusão dos trabalhos duplicados, sendo préselecionados 364 artigos. Após a sua leitura, foram excluídos os artigos que abordavam participação da comunidade em fóruns comunitários não relacionados com a saúde; participação dos usuários em decisões terapêuticas, em grupos de auto-cuidado e no controle de doenças; participação em colegiados de gestão em outros países; participação no processo de formulação de política de saúde através dos movimentos sociais, sem referir conselho ou conferência; percepção da comunidade e de profissionais de saúde sobre o conselho; e trabalhos sobre a participação da sociedade na fiscalização da execução orçamentária, financeira e fiscal do SUS, a partir de outros mecanismos que não conselhos ou conferências de saúde. Seguida esta dinâmica, restaram 152 artigos, sendo 84 provenientes da base SciELO, 44 da LILACS e 24 do portal de periódicos da CAPES.

Os 152 artigos foram lidos na íntegra, sendo extraído um conjunto de informações que vieram a integrar uma matriz. Esta, por sua vez, dispunha das seguintes variáveis: identificação/ título, ano de publicação, veículo de divulgação, autores, procedência institucional dos autores, objeto de estudo, esfera do conselho/conferência de saúde, tipo de estudo e abordagem teóricometodológica utilizada.

Dessa forma, foi possível identificar, no conjunto dos artigos selecionados, aqueles que explicitaram, no seu conteúdo, o referencial teóricometodológico utilizado. Neste estudo, adotou-se a concepção de referencial teórico-metodológico como uma trama articulada de conceitos vinculados a uma teoria capaz de proporcionar ruptura com o senso comum ${ }^{18}$. A ruptura epistemológica com o senso comum significa pôr em suspenso as pré-construções vulgares e os princípios geralmente aplicados nas realizações dessas construções ${ }^{19}$.

\section{Resultados e discussões}

\section{Indicadores bibliométricos}

A produção científica sobre participação em conselhos e conferências de saúde apresenta uma tendência de aumento gradativo no número de artigos ao longo do período estudado (Gráfico 1), embora tenha havido uma variação, ano a ano, com momentos de maior número de publicações. No ano de 2012 foram identificados 20 artigos, enquanto outros períodos não apresentaram registro de publicações, tal como um quatriênio na década de 1990.

A análise das instituições, programas de pósgraduação, departamentos ou graduações aos quais os autores dos estudos estão vinculados, revela que a maioria destes se vincula a instituições e programas da área das ciências da saúde (122 $=80,3 \%)$, destes a maioria é da subárea Saúde Coletiva $(67=54,9 \%)$ seguida da Enfermagem $(24=19,7 \%)$. Também foram identificados autores que procedem de instituições e programas da área de ciências humanas $(21=13,8 \%)$, ciências sociais aplicadas $(8=5,2 \%)$ e até mesmo as ciências agrárias $(1=0,7 \%)$. Esse achado indica a maneira interdisciplinar como as instâncias participativas do SUS vêm sendo tratadas pelas instituições de pesquisa. Aponta, igualmente, a centralidade do tema da participação social no âmbito da saúde coletiva.

Os artigos analisados foram publicados em 46 periódicos dos quais cinco concentram a maioria (94 $=61,8 \%$ ), quais sejam: Ciência \& Saúde Coletiva $(29=19,1 \%)$, Saúde e Sociedade (27 = 17,8\%), Cadernos de Saúde Pública (17 = $11,2 \%)$, Saúde em Debate $(11=7,2 \%)$ e Physis $(10=6,5 \%)$.

Os conselhos são mais frequentemente estudados $(92=60,5 \%)$ que as conferências $(22=$ $14,5 \%)$, principalmente os conselhos municipais $(59=64 \%)$ sendo que nenhum estudo aborda o Conselho Nacional de Saúde, enquanto que, no grupo de estudos sobre as conferências, predominam artigos sobre as conferências nacionais $(13=59 \%)$, conforme apresentado na Tabela 1 . O fato dos conselhos serem mais frequentemente estudados pode estar relacionado especialmente à sua qualidade de ser um colegiado permanente, enquanto as conferências ocorrem somente uma vez a cada quatro anos, em cada esfera de governo. No Brasil, somam 5.570 conselhos municipais de saúde ${ }^{20}$, o que explica a quantidade expressiva de estudos sobre esse espaço colegiado no âmbito municipal. 


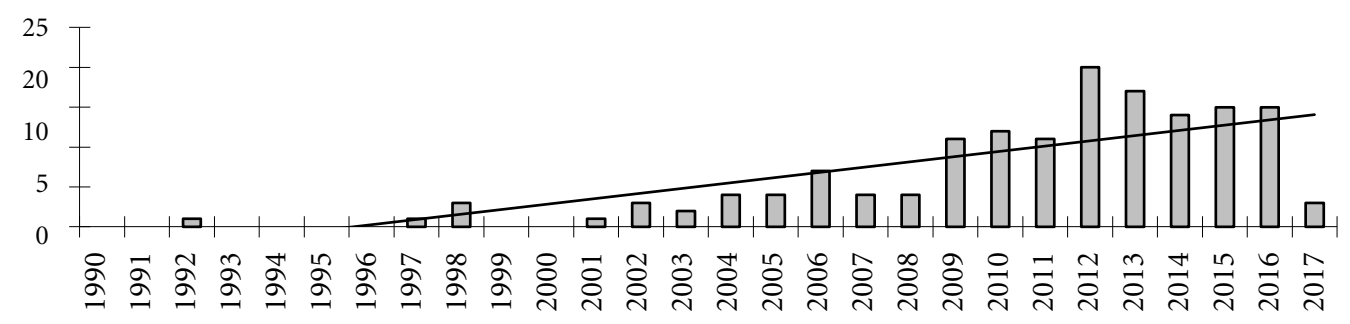

Gráfico 1. Linha de tendência da produção científica brasileira sobre participação em saúde desde a Lei $8.142 / 1990$.

Fonte: Elaboração própria.

Tabela 1. Distribuição dos artigos segundo objeto de estudo.

\begin{tabular}{|c|c|c|c|c|c|}
\hline \multirow[b]{2}{*}{ Esfera de governo/gestão do SUS } & \multicolumn{4}{|c|}{ Objeto de estudo } & \multirow[b]{2}{*}{ Total } \\
\hline & $\begin{array}{c}\text { Conselho } \\
(92)\end{array}$ & $\begin{array}{c}\text { Conferência } \\
\text { (22) }\end{array}$ & $\begin{array}{c}\text { Conselho/ } \\
\text { Conferência } \\
(4)\end{array}$ & $\begin{array}{l}\text { Outros: estudos de } \\
\text { revisão, reflexão, } \\
\text { debate (34) }\end{array}$ & \\
\hline Local (26) & 25 & 1 & - & - & \\
\hline Municipal (68) & 59 & 8 & 1 & - & \\
\hline Estadual (6) & 4 & - & 2 & - & \\
\hline Nacional (13) & - & 13 & - & - & \\
\hline Estudo em mais de uma esfera (5) & 4 & - & 1 & - & \\
\hline $\begin{array}{l}\text { Outros: estudos de revisão, } \\
\text { reflexão, debate ( } 34 \text { ) }\end{array}$ & - & - & - & 34 & \\
\hline Total & & & & & 152 \\
\hline
\end{tabular}

Fonte: Elaboração própria.

O estudo de caso consiste na abordagem predominante $(79=52 \%)$, destes a maioria discorre somente sobre conselho $(70=88,6 \%)$. Enquanto a pesquisa documental ocorre mais frequentemente sobre conferências $(09=56,2 \%)$ (Tabela 2).

\section{Abordagens metodológicas}

Uma novidade evidenciada nesse trabalho consiste na utilização de abordagens da pesquisa avaliativa nos estudos sobre conselhos e conferências de saúde ${ }^{21-26}$. Contudo, a perspectiva adotada nas pesquisas avaliativa dá conta somente de dimensões específicas da implantação e do funcionamento do conselho, mediante a utilização de critérios, normas, indicadores e modelos, não sendo identificadas pesquisas com esse desenho metodológico que avaliem os resultados dos con- selhos e das conferências de saúde na política de saúde ou na saúde da população.

Embora seja fundamentalmente necessário saber o impacto da participação social, especialmente considerando a dimensão que esses espaços participativos representam no cenário brasileiro e do elevado investimento de diversas ordens (política, econômica, social, ideológica, cultural, subjetivo) que a sociedade faz nos conselhos e nas conferências de saúde, os resultados da participação social na política de saúde e na saúde da população ainda são pouco conhecidos no Brasil ${ }^{5,23}$.

Trata-se de uma lacuna de relevância estratégica para o campo da saúde coletiva que dificilmente poderá ser respondida com um estudo isolado. No entanto, foi possível identificar estudos ${ }^{27-32}$ que avançaram nessa direção. O caminho metodológico adotado nessas iniciativas foi semelhante e consistiu em acompanhar, consecutivamente, a in- 
Tabela 2. Distribuição dos artigos segundo abordagem e tipo de estudo.

\begin{tabular}{lccccc}
\hline \multicolumn{1}{c}{ Tipo de estudo } & $\begin{array}{c}\text { Abordagem } \\
\text { teórica (12) }\end{array}$ & $\begin{array}{c}\text { Abordagem } \\
\text { empírica } \\
(\mathbf{8 7})\end{array}$ & $\begin{array}{c}\text { Abordagem teórica e } \\
\text { empírica (24) }\end{array}$ & $\begin{array}{c}\text { Outros } \\
(29)\end{array}$ & Total \\
\hline Estudo de caso (79) & - & $(56)$ & $(23)$ & - \\
Estudo documental (16) & - & $(15)$ & $(1)$ & - \\
Relato de experiência (8) & - & $(8)$ & - & - \\
Estudo de avaliação (6) & - & $(6)$ & - & - \\
Relato de caso e pesquisa ação (2) & - & $(2)$ & - & $(22)$ \\
Estudo de reflexão, ensaio, debate (34) & $(12)$ & - & - & $(7)$ \\
Estudo de revisão de literatura (7) & - & - & & \\
Total & & & & - \\
\hline
\end{tabular}

Fonte: Elaboração própria.

corporação das deliberações do controle social no ciclo da política de saúde, levando em consideração a atuação conjunta de arenas e atores (comissão intergestora, conselho e conferência de saúde, secretaria de saúde e câmara dos vereadores ou assembléia legislativa) envolvidos no processo de construção da política de saúde.

Essa estratégia possibilita superar análises fragmentadas e alienantes que impedem capturar os resultados da participação obtidos no decurso do tempo e que acabam sendo ofuscados nos trâmites das diversas mãos que conduzem as decisões em torno da política de saúde. Em consonância com Schraiber ${ }^{33}$, trata-se de estudar a noção de uma totalidade delimitada da participação em saúde, sem que isso figure na idéia de exaustão de variáveis.

A possibilidade real de produzir conhecimento sobre os resultados da participação nas políticas de saúde mediante estudo de caso longitudinal retrospectivo, considerando os atores e arenas relacionados com a construção da política de saúde, desautoriza os argumentos de que a avaliação do impacto da participação pressuponha, necessariamente de modelos robusto ${ }^{5}$, normativo e generalizável ${ }^{23}$. Até porque modelos assim, dificilmente permitiriam apreender a totalidade que envolve o processo participativo e seus desdobramentos e cuja expressão também se apresenta na heterogênea e variante conjuntura de cada município e estado brasileiro.

\section{Aportes teórico-conceituais}

Ao proceder a uma leitura extensiva dos artigos constatou-se, ainda, que dos 111 estudos com base empírica, somente oito (7,2\%) fundamentam, explicitamente, suas análises em constructos teó$\operatorname{ricos}^{27,29,34-39}$. Assim, a maioria $(103=92,8 \%)$ dos artigos busca, sobretudo descrever o fenômeno da participação. A mera descrição constitui numa contribuição parcial para a produção científica, já que para construir um objeto científico é necessário considerar os componentes empíricos e teóricos do fenômeno. A escassa publicação de estudos que apresentaram, em seu texto, os aportes teórico-metodológicos utilizados na análise de dados indicam que a produção científica sobre conselho e conferência de saúde no Brasil está marcada pela rarefação teórica ou conceitual, cujo reflexo se dá na superficialidade do conhecimento construído sobre o tema ${ }^{33}$.

No Quadro 1, estão apresentados os componentes teóricos identificados nos estudos empíricos sobre conselho e conferência de saúde.

As premissas teóricas identificadas nos estudos pertencem à matriz sociológica e da ciência política, sendo evidenciados modelos teóricos, conceitos e teorias de médio alcance, uma vez que o uso de uma grande teoria somente pode ser verificado através da mediação de outras mais específicas capazes de estreitar o seu domínio dando conta de fenômenos no nível concreto ${ }^{49}$. Os conceitos utilizados estão filiados às abordagens estruturalista, pós-estruturalista e neo-institucionalista. Destacase que não foram encontrados estudos que adotassem diretamente as clássicas teorias sociais de Weber e Durkheim. Tampouco foram identificadas abordagens que combinassem, no seu referencial teórico, mais de uma perspectiva de análise. Os artigos recorreram aos enfoques de autores como Foucault, Habermas, Gramsci, Kingdon, Olson, Maslow, Collier, Lourau e Lapassade e Testa, não sendo identificados estudos que fizessem uso da análise sócio-histórica (Bourdieu).

A adoção de teorias de matriz sociológica que tomam como base a tradição do conflito permite 
Quadro 1. Abordagens teóricas utilizadas nos artigos sobre conselhos e conferências de saúde.

A abordagem estruturalista fundamenta-se na historicidade, dinamicidade e totalidade da dialética marxista. Tratase de uma teoria sistêmica que possibilita compreender a práxis humana. A partir dessa matriz marxista, Gramsci ${ }^{40}$ desenvolve o conceito de Estado ampliado, isto é, aquele que acomoda, além da sociedade política, a sociedade civil como parte do Estado. A primeira formada pelo conjunto de mecanismos através dos quais a classe dominante detém o monopólio legal da coerção, aqueles habitualmente identificados como governo. Já a sociedade civil é formada como uma decisiva arena da luta de classes, na qual os diferentes grupos sociais lutam para conservar ou conquistar a hegemonia.

Micropoder - Foucault ${ }^{41}$

O pós-estruturalista Foucault evidencia formas de exercício de poder diferentes do exercido no aparelho do Estado e cujo funcionamento assemelha-se a uma rede de micropoder molecular que se estende por toda a sociedade.

Agenda governamental - Kingdon ${ }^{42}$

O processo de conformação da agenda governamental, ancorada na teoria do ciclo da política pública, articula três fluxos, o de transformação de uma questão proveniente do ambiente social em problema, o da seleção de soluções direcionadas a esse problema, e as influências políticas envolvidas na inclusão do problema na agenda do governo. Para Kingdon, o processo decisório de formulação e implementação da política é influenciado pelo envolvimento de diversos atores que aproveitam de uma situação oportuna para pressionar o governo a incluir problemas na agenda política. Esse entendimento vincula-se à abordagem neo-institucionalista cuja preocupação consiste em analisar as relações entre o Estado, a sociedade e a formulação de política, em especial procura explicar como as instituições desenvolvem estratégias políticas e influenciam os resultados políticos.

Análise institucional - Instituinte/instituído - Lourau e Lapassade ${ }^{43}$

A dialética instituinte (processo) e instituído (forma) é útil para analisar situações de institucionalização. No caso da análise da participação institucionalizada, essa perspectiva é marcada por tensões para adquirir mais participação e inovação estratégica social e institucional. Enquanto na primeira há preponderância da direcionalidade participativa e da condução governamental compatível e coerente com as razões, modos e meios da democracia direta e indireta, na segunda predomina a atuação figurativa do controle social e a direção do governo é autônoma, operando com agenda própria e dissociada das instâncias de participação.

Momento crítico - Collier e Collier ${ }^{44}$

Define-se como momento crítico, um período de significativa mudança seja ela revolucionária ou provocada por reforma institucional, com tempo de duração que pode ser de anos ou até de décadas, é uma situação de transição política e/ou econômica que ocorre de modo diferente entre países, estados, regiões ou cidades. Esse processo de mudança deixa um legado que conduz os políticos a escolhas e decisões sucessivas ao longo do tempo, visando à reprodução desse legado. Teoria de grupos sociais - Olson ${ }^{45}$

A teoria está ancorada na lógica da ação coletiva e busca responder o que leva os indivíduos se associarem e se manterem associados. Para responder essa questão, Olson partiu da perspectiva da racionalidade coletiva, considerando que se todos cooperassem também todos ganhariam. Entretanto, como isso nem sempre acontece, os indivíduos agem racionalmente medindo os custos e benefícios de suas ações coletivas em organizações ou grupos. Logo, forma-se uma relação contraditória entre uma racionalidade individual e racionalidade coletiva. Essa abordagem de grupos sociais está inserida na teoria da escolha racional que pressupõe que os indivíduos agem de forma deliberada para potencializar suas vantagens.

Teoria motivacional - Maslow ${ }^{46}$

Essa teoria parte da perspectiva da psicologia e busca identificar os motivos que levam um indivíduo a ter um comportamento participativo com vistas a encontrar soluções para problemas coletivos. De acordo com essa teoria, a motivação é o resultado de estímulos provenientes do ambiente (externo) ou gerados internamente nos processos mentais do indivíduo (interno) que agem com força sobre os indivíduos, levando-os à ação.

Teoria do Agir comunicativo - Habermas ${ }^{47}$

O poder comunicativo consiste na possibilidade de formação da vontade política a partir do agir comunicativo dos indivíduos e, dessa forma, ser capaz de pressionar as instituições a incorporar demandas em sua agenda. A ação comunicativa se expressa em um ambiente em que os participantes envolvidos apresentam igual condição para opinar, sem qualquer tipo de coerção. A decisão ocorre com base no consenso ou no acordo possível em torno do melhor argumento e sua legitimidade se fundamenta na possibilidade de todos os interessados participarem do processo comunicativo. O agir comunicativo assenta sua matriz conceitual na teoria crítica da escola de Frankfurt.

Poder em saúde - Testa ${ }^{48}$

A partir de uma contribuição mais voltada para a área da saúde, o autor analisa o uso concreto dos recursos de poder no âmbito das organizações, distinguindo três formas de poder em saúde, o poder técnico, administrativo e político. O poder técnico pode ser entendido como a capacidade que tem um ator de manusear e utilizar informações (epidemiológica, sanitária, administrativa). O poder administrativo é quando o ator é capaz de manusear recursos (humanos, financeiros, tecnológicos, administrativo) e o poder político consiste na capacidade de mobilizar grupos sociais. 
uma profícua análise da participação nas instâncias deliberativas, já que o procedimento adotado para deliberação nesses espaços baseia-se na votação que, em grande medida, é antecedida por disputas de interesses e discursos conflitantes, que mais se assemelham ao agir estratégico do que a racionalidade fundada no consenso. Nesta perspectiva, considera-se que o pensamento estratégico de $\mathrm{Testa}^{48}$ possui um potencial analítico para a análise do processo político de participação em saúde. Vinculado à corrente marxista, a categoria central desse aporte teórico-metodológico é o poder em saúde, na forma como ele é disputado e apropriado nos âmbitos societário e no espaço social do setor saúde ${ }^{50}$.

Em contrapartida, a adoção pura da teoria do agir comunicativo, no que se refere às categorias "poder" e "ação comunicativa" para análise da participação em conselho e conferência de saúde, deve partir da análise de um caso concreto, que reúna condições reais para seu uso. Já que a perspectiva da ação comunicativa pressupõe uma comunidade de diálogo baseada no consenso e cuja inviabilidade se opera num espaço marcado pela assimetria de poder e pela predominância da cultura política tradicional autoritária, corporativa e de cooptação. O uso cauteloso da perspectiva do agir comunicativo de Habermas nos estudos de colegiados participativos foi igualmente indicado por Muller Neto e Artmann ${ }^{51}$. Ao analisar o potencial de conceitos Habermasianos para análise de conselhos e conferências, tais autores ressaltaram a necessidade destes conceitos serem mediados e contextualizados.

A análise das relações de poder na dinâmica interna dos conselhos e nos espaços das conferências de saúde, bem como entre estes canais de participação com os atores sociais e estatais que disputam a definição e a condução da política de saúde pode se beneficiar das abordagens de Foucault e de Testa sobre o poder. Isso porque ambas as perspectivas reconhecem a existência e a relevância do conflito como um aspecto inerente à realidade concreta das sociedades democráticas. Entretanto, a análise Testiana do poder, especialmente quando referida à tipologia do poder técnico, administrativo e político, delimita o uso dos recursos de poder ao âmbito das organizações ${ }^{39}$. Enquanto do ponto de vista Foucaultiano, é possível analisar, por exemplo, formas de exercício de poder diferentes daquelas exercidas na máquina estatal ${ }^{35}$.

O modelo teórico de Kingdon ${ }^{42}$ é útil para analisar como determinada demanda social se transforma em um problema político. Portanto, permite evidenciar a capacidade dos conselhos e das conferências de incluir problemas de saúde, considerados prioritários, na agenda política do governo $^{29}$. Da mesma forma que o modelo teórico de Kingdon ${ }^{42}$, o pensamento estratégico de Testa ${ }^{48}$ possibilita analisar a participação dos conselhos na construção da política de saúde, por exemplo. Entretanto, o objeto central da análise proporcionada pelo pensamento estratégico de Testa ${ }^{48}$ é a relação de poder, o processo político e sua relação com a produção de fatos políticos, incluindo ainda a análise de conjunturas e suas relações com a política de saúde ${ }^{52}$. Assim, com a perspectiva de Kingdon ${ }^{42}$ é possível desenvolver uma análise de política de saúde e com o pensamento estratégico de Testa, uma análise política em saúde.

Os estudos cuja preocupação central consiste em compreender as razões que levam os atores a se engajarem em movimentos sociais podem ser beneficiados pela teoria motivacional de Maslow ${ }^{46}$ e pela perspectiva da ação coletiva, na qual está ancorada a teoria dos grupos sociais de Olson ${ }^{45}$. Destaca-se que esses enfoques adotam o indivíduo, como nível de análise, de modo que o objeto de estudo central adotado nestes aportes teóricos consiste no conselheiro ou delegado da conferência, em detrimento do conselho ou da conferência ${ }^{7}$.

Os conceitos de Estado ampliado, sociedade civil e sociedade política de Gramsci ${ }^{40}$ têm sido utilizados especialmente nos estudos de reflexão para compreender os canais de participação social, já que configuram espaços híbridos de encontro de atores governamentais e sociais. Contudo, a operacionalização desses conceitos nos estudos empíricos sobre conselhos e conferências de saúde é dificultada pela amplitude dessas categorias Gramscianas, que têm como base a noção da luta de classes sociais.

Neste sentido, independente da abrangência da premissa teórica utilizada nas pesquisas sobre participação em saúde sejam teorias de grande e médio alcance $\left(\right.$ Gramsci $^{40}$, Olson $^{45}$ e Maslow $^{46}$ ), sejam modelos teóricos (Kingdon ${ }^{42}$ ) ou ainda categorias analíticas vinculadas a uma teoria (Habermas ${ }^{47}$, Testa $^{48}$, Foucault ${ }^{41}$, Collier ${ }^{44}$, Lourau e Lapassade ${ }^{43}$ ), importa manter uma contínua coerência entre a metodologia escolhida e a dinâmica do objeto. Esta vigilância epistemológica possibilita produzir o estranhamento nas situações corriqueiras, necessário para aprofundar o conhecimento existente, evitando o automatismo que aniquila a potência reflexiva da pesquisa ${ }^{19}$. 


\section{Considerações Finais}

No Brasil há uma vasta publicação de artigos sobre conselhos e conferências de saúde, no entanto, esses estudos apresentam baixo adensamento conceitual, ou seja, fazem pouca articulação entre a formulação de base empírica e uma dada referência teórica ${ }^{33}$. A rarefação teórica dessas pesquisas indica, inclusive, que o conhecimento produzido sobre o tema ainda é superficial, necessitando de um maior aprofundamento epistemológico capaz de produzir interpretações contextualizadas dos dados empíricos.

A análise da participação mediante mais de uma perspectiva teórica (estruturalista, pós-estruturalista, neo-institucionalista) indica que não há um único modelo finalístico e unanimemente aceito para abordar os espaços participativos. Assim, a construção do conhecimento sobre conselhos e conferências pode se beneficiar das contribuições das ciências sociais e políticas e também de conceitos e modelos desenvolvido por autores do planejamento em saúde.

Esse estudo apresenta a limitação de ter utilizado como fonte de pesquisa somente a produção de artigos, deixando de lado teses, dissertações e livros que, reconhecidamente, reúnem uma massa crítica relevante sobre a temática. Também importa considerar que, apesar do esforço de aglutinar a totalidade de estudos publicados sobre conselho e conferência de saúde, a busca ocorreu somente nas três principais bases de dados bibliográficos, e dessa forma, a estratégia metodológica adotada não pressupõe uma revisão exaustiva de todos os artigos já produzidos. Destaca-se, finalmente, que foram considerados artigos que fizeram uso de aportes teóricos somente aqueles que explicitaram, nomeadamente, os referenciais em seu texto.

$\mathrm{O}$ estudo desperta para alguns aspectos importantes a serem aprofundados pela produção científica brasileira sobre conselhos e conferências de saúde. Tais aspectos situam-se no âmbito do impacto da participação social institucionalizada nas políticas de saúde; além da questão pontual de existir poucos estudos sobre o conselho nacional de saúde, instância máxima de participação na política nacional de saúde, de importância estratégica para o SUS; e, sobretudo a baixa densidade teórica dos estudos sobre o tema. Esses elementos abrem novas perspectivas para futuras pesquisas.

\section{Colaboradores}

BT Silva colaborou na concepção, análise e interpretação dos dados, na escrita e revisão crítica do artigo. IMSO Lima contribuiu no planejamento, interpretação dos dados, revisão crítica e na aprovação da versão final do artigo. 


\section{Referências}

1. Paim JS. Reforma sanitária brasileira: Contribuição para a compreensão e crítica. Salvador: EDUFBA, Rio de Janeiro: Fiocruz; 2010.

2. Bispo Junior JP. Participação social e relações de poder no Conselho Estadual de Saúde da Bahia [tese]. Rio de Janeiro: Escola Nacional de Saúde Pública Sergio Arouca; 2013.

3. Oliveira TA. Participação do Conselho e das Conferências de Saúde no ciclo da Política Estadual de Saúde Mental (Bahia, 2001-2013) [dissertação]. Salvador: Universidade Federal da Bahia; 2015.

4. Labra ME. Política Nacional de Participação na Saúde: entre a utopia democrática do controle social e a práxis predatória do clientelismo empresarial. In: Fleury $S$, Lobato LVC, organizadores. Participação, democracia e saúde. Rio de Janeiro: Cebes; 2010. p. 176-203.

5. Serapioni M. Os desafios da participação e da cidadania nos sistemas de saúde. Cien Saude Colet 2014; 19(12):4829-4839.

6. Bispo Junior JP, Gerschman S. Legitimidade da representação em instâncias de participação social: o caso do Conselho Estadual de Saúde da Bahia, Brasil. Cad Saúde Pública 2015; 31(1):183-193.

7. Farias Filho MC, Silva AN, Mathis A. Os limites da ação coletiva nos Conselhos Municipais de Saúde. Cien Saude Colet 2014; 19(6):1911-1919.

8. Oliveira LC. As práticas de participação institucionalizadas e sua interface com a cultura politica: um olhar sobre o cotidiano de um conselho municipal de saúde no nordeste brasileiro [tese]. Rio de Janeiro: Universidade Estadual do Rio de Janeiro; 2006.

9. Espiridião MA. Controle social do SUS: conselhos e conferências de saúde. In: Paim JS, Almeida Filho N. Saúde coletiva: teoria e prática. Rio de Janeiro: MedBook; 2014.

10. Cavalcanti MLT, Cabral MHP, Antunes LR. Participação em saúde: uma sistematização de artigos publicados em periódicos brasileiros - 1988/2005. Cien Saude Colet 2012; 17(7):1813-1823.

11. Rolim LB, Cruz RSBLC, Sampaio KJAJ. Participação popular e o controle social como diretriz do SUS: uma revisão narrativa. Saúde Debate 2013; 37(96):139-147.

12. Bastos Filho RA, Cunha WA, Oliveira AR. Conselhos Gestores de Saúde no Brasil: uma meta-análise da produção científica a partir da $12^{\mathrm{a}}$ Conferência Nacional de Saúde. Rev Adm Roraima 2015; 5(2):164-188.

13. Paiva FS, Stralen CJ, Costa PHA. Participação social e saúde no Brasil: revisão sistemática sobre o tema. Cien Saude Colet 2014;19(2):487-498.

14. Maeyama MA, Bertucci FMD, Loblein JP, Dolny LL, Nilson LG, Munaro CA, Cutolo LRA. Participação social na saúde no Brasil - revisão integrativa. Rev Bras Tecnol Soc 2016; 3(1):23-36.

15. Melo RC, Possa LB. Democracia no SUS, como estamos? Um debate sobre a participação social a partir da literatura recente. Saúde Redes 2016; 2(4):393-408.

16. Gomes ACS, Carvalho FR, Bernardo GN, Oliveira LDC, Lima TS, Mendes MM. O papel das ouvidorias e dos conselhos de saúde no SUS: uma revisão integrativa de literatura. Rev Eletr Gestão Saúde 2017; 8(1):140-161.
17. Observatório de Análise Política em Saúde (OAPS) Mudanças na Política Nacional de Saúde Mental: participação social atropelada, de novo [Internet]. 2018 [acessado 15 Mar 2018]. Disponível em: https://www. analisepoliticaemsaude.org/oaps/boletins/edicoes/31/\#114

18. Laville C, Dionne J. A construção do saber: manual de metodologia da pesquisa em ciências humanas. Porto Alegre: Artmed, Belo Horizonte: Editora UFMG; 2008.

19. Bourdieu P, Chamboredon JC, Passeron JC. O fato é conquistado contra a ilusão do saber imediato. In: Bourdieu P, Chamboredon JC, Passeron JC. A profissão do sociólogo. Preliminares epistemológicas. Petrópolis: Vozes; 1999. [indicar paginação]

20. Moreira MR, Escorel S. Conselhos Municipais de Saúde do Brasil: um debate sobre a democratização da política de saúde nos vinte anos do SUS. Cien Saude Colet 2009; 14(3):795-805

21. Vieira M, Calvo MCM. Avaliação das condições de atuação de Conselhos Municipais de Saúde no Estado de Santa Catarina, Brasil. Cad Saúde Pública 2011; 27(12):2315-2326.

22. Coelho VSP, Ferraz A, Fanti F, Ribeiro M. Mobilização e participação: Um jogo de Soma Zero? Novos Estudos 2010; 86:121-139.

23. Vaz ACN. Participação política, efeitos e resultados em políticas públicas: notas crítico-analíticas. Opinião Pública 2011; 17(1):163-205.

24. Batista AA, Muniz JN, Ferreira Neto JA, Cotta RMM. A Contribuição da Pesquisa Avaliação para o Processo de Implementação do Controle Social no SUS. Saúde Soc 2010; 19(4):784-793.

25. Ouverney AM, Moreira MR, Ribeiro JM. Democratização e educação permanente: percepção de egressos do QualiConselhos sobre contribuições aos conselhos de saúde. Saúde Debate 2016; 40(esp.):186-200.

26. Gonçalves AO, Gonçalves RS, Tavares AL. O Olhar dos Conselheiros de Saúde Sobre os Relatórios de Prestação de Contas no Município de Natal (Rio Grande do Norte), Brasil. Saúde Soc 2011; 20(13):659-672.

27. Oliveira AGB, Conciani ME. Participação social e reforma psiquiátrica: um estudo de caso. Cien Saude Coley 2009; 14(1):319-331.

28. Alves-Sousa RA, Saliba O. A saúde bucal em pauta: análise de registros dos Conselhos Municipais de Saúde de municípios pertencentes à 17a Regional de Saúde do Estado do Paraná, Brasil. Cad Saúde Pública 2003; 19(5):1381-1388.

29. Oliveira TA, Teixeira CF. Participação das instâncias de controle social na Política de Saúde Mental da Bahia, 2001-2013. Saúde Debate 2015; 39(esp.):132-144.

30. Kleba ME, Zapiron K, Comerlatto D. Processo decisório e impacto na gestão de políticas públicas: desafios de um Conselho Municipal de Saúde. Saúde Soc 2015; 24(2):556-567.

31. Bispo Junior JP, Pinheiro GML. Participação social e relação de poder na definição das políticas de saúde no estado da Bahia. Público Privado 2016; 27:17-37. 
32. Ditterich RG, Ditterich ACR, Baldani MH. A política de saúde bucal em pauta no Conselho Municipal de Saúde no Município de Nova Friburgo - RJ. Rev Odontol UNESP 2015; 44(3):143-151.

33. Schraiber LB. Engajamento ético-político e construção teórica na produção científica do conhecimento em saúde coletiva. In: Baptista TWF, Azevedo CS, Machado CV, organizadores. Políticas, planejamento e gestão em saúde: Abordagens e métodos de pesquisa. Rio de Janeiro: Fiocruz; 2015. p. 33-57.

34. Fernandes ASA. Conselhos Municipais: participação, efetividade e institucionalização - a influência do contexto político na dinâmica dos conselhos - os casos de Porto Alegre e Salvador. Cad EBAPE 2010; 8(3):438-452.

35. Wendhalsen ALP. Relaciones de poder y democracia en los consejos de salud en Brasil: estudio de un caso. Rev Española Salud Pública 2006; 80(6):697-704.

36. Farias Filho MC, Silva AN, Mathis A. Os limites da ação coletiva nos Conselhos Municipais de Saúde. Cien Saude Colet 2014; 19(6):1911-1919.

37. Santos SF, Vargas AMD, Lucas SD. Conselheiros Usuários do Conselho Municipal de Saúde de Belo Horizonte: características sociais e representatividade. Saúde Soc 2011; 20(2):483-495.

38. Muller Neto JS, Artmann E. Discursos sobre o papel e a representatividade de conferências municipais de saúde. Cad Saúde Pública 2014; 30(1):68-78.

39. Miranda AS, Moreira AEMM, Cavalcanti CGCS, Bezerra FM, Oliveira JC, Rezende R. Discursos práticos sobre ocorrências, processos decisórios e decorrências de Conferências Municipais de Saúde. Interface (Botucatu) 2016; 20(58):559-571.

40. Gramsci A. Maquiavel, a política e o Estado Moderno. Rio de Janeiro: Civilização Brasileira; 1980.

41. Foucault M. Microfísica do poder. Rio de Janeiro: Edições Graal; 1979.

42. Kingdon JW. Agendas, Alternatives and Public Policies. United States of America: Addison-Wesley Longman; 1995.

43. Lourau R. A Análise Institucional. Petrópolis: Vozes; 1975.
44. Collier D, Collier R. Shaping the political arena. Critical junctures, the labor movement, and regime dynamics in Latin America. Princeton: Princeton University Press; 1991.

45. Olson M. A lógica da ação coletiva: os benefícios públicos e uma teoria dos grupos sociais. São Paulo: EDUSP; 1999.

46. Maslow AH. A theory of human motivation. Psychological Review 1943; 50:390-396.

47. Habermas J. Teoria da la Acción Comunicativa. Madri: Ed. Taurus Humanidades; 1987.

48. Testa M. Pensamento estratégico e lógica da programação. O caso da Saúde. São Paulo, Rio de Janeiro: Ed. Hucitec; 1995.

49. Bunge M. Os conceitos de modelo. Modelos na ciência teórica. In: Bunge M. Teoria e realidade. São Paulo: Perspectiva; 1974. p. 11-40.

50. Federico L. Análise política em saúde: a contribuição do pensamento estratégico. Salvador: EDUFBA; 2015.

51. Muller Neto JS, Artmann E. Política, gestão e participação em Saúde: reflexão ancorada na teoria da ação comunicativa de Habermas. Cien Saude Colet 2012; 17(12):3407-3416.

52. Teixeira CT, Silveira P, organizadores. Glossário de análise política em Saúde. Salvador: Edufba; 2016.

Artigo apresentado em 10/05/2018

Aprovado em 24/04/2019

Versão final apresentada em 26/04/2019

Editores chefes: Romeu Gomes, Antônio Augusto Moura da Silva 